\title{
Riscos e agravos à saúde e à vida dos trabalhadores das indústrias madeireiras de Mato Grosso
}

\author{
Risks and injuries to the health and life of \\ the workers of the lumber industries of Ma to Grosso
}

Wanderlei An tonio Pignati 1

Jor ge Mesquita Huet Machado 2

1 Instituto de Saúde Coletiva da UFMT. Av. Fernan do Correia, Campus Un iversitário, Coxipó, 78060-900, Cuiabá MT.

pignatimt@terra.com.br 2 Coordenação de Saúde do Trabalhador, Fiocruz/ DIREH, Rio de Ja neiro.
Abstract In the current phase of anthropoid occupation of the Amazonia, called agro-industrial-forest development, the sector of the lumber industry, one of polar regions of the economy of the state of Ma to Grosso provokes great nega tive impact in the environment and the health. In the study were analyzed the conditions of risk of 1.389 industries and evaluated 4.381 workers of the total of 21.607 that wo rked du ring the year of 2000. Theprecaution of wo rk was observed in all places, in varied degrees, demonstra ting that yet, the more the industry is moved away from the headquarters of the cities, the conditions of work, salary and healthy becomes worse. The results had shown that $11 \%$ of the workers in active were mutilated to others $25 \%$ presen ted other sequels of industrial accidents and $28 \%$ were with column deformities of the vertebral column, amongst other injuries diagnosed. The research pointed with respected to the maximum exploration of the force of the work, irresponsible patron with the situation risks and still the insufficient organization of the workers from the lumber industries of this region, who express the structural social violence of this occupation and destruction of the Amazonia.

Key word s Risk analysis, Wo rkers' health, Lumber industry
Resumo Na atual fase de ocupação antrópica da Amazônia, ou desenvolvimento agroindustrialflorestal, o setor da indústria madei reira, um dos pólos da economia do Estado de Mato Grosso, provoca grande impacto nega tivo no ambien te e na saúde. No estudo foram analisadas as situações de risco de 1.381 indústrias e avaliados 4.381 trabalhadores dos 21.607 que laboravam du rante $o$ ano de 2000. Foi observada a precarização do trabalho em todos os locais, em graus variados, demonstrando-seque, quanto mais as indústrias se afastam das sedes dos municípios, pioram as condições de trabalho/salário/saúde. Os resultados apo nta ram que $11 \%$ dos trabalhado res estavam mutilados, outros $25 \%$ apresen tavam outras seqü elas de aciden tes de tra balho e $28 \%$ estava $m$ com deformidades de coluna vertebral, dentre outros agravos diagnosticados. A pesquisa apontou pa ra a máxima explo ração da força de trabalho, desresponsabilização patronal com as situações de riscos e ainda a insuficiente organização dos trabalhadores e precária regulação e fiscalização do Estado, acarretando desproteção social dos trabalhadores das indústrias madei rei ras nessa região, expressando a violência social estrutural dessa ocupação/destruição da Amazônia.

Palavras-chave Análise de risco, Saúde do trabalhador, Indústria da madeira 


\section{Introdução}

A ocupação antrópica da região Amazônica foi motivada por vários fatores, entre os quais se destacam a migração de trabalhadores na bu sca por subsistência baseada no extrativismo de produtos florestais e minerais e a ocupação de terras públicas por posseiros (ocupantes de pequenas áreas sem titulação de propriedade), pelas colonizadoras públicas e privadas e pelas frentes de abertura/construção de estradas e hidrelétricas. A atual fase de ocupação, de des envolvimento agroindustrial-florestal ou de tra n s formação da natureza e substituição desta por processos industriais e agropecuários, tem como fren te às indústrias de mineração, de madeira e de alimentos, as culturas de soja, arroz, milho, algodão, cana de açúcar e a pecuária bovina (Nascimen to \& Drummond, 2003; Mello \& Théry, 2003)

Os trabalhadores nas madei reiras, os ribeirinhos, os agricultores familiares ou posseiros são "consumidos" neste processo de de senvolvimento. Interpretando os ensinamentos de Milton Santos (2002), pode-se definir o território amazônico como um espaço socialmen te construído, onde o homem inscreveu suas lutas, apoderou-se do natural e o transformou em natu reza humanizada, seja para produzir bens para sua reprodução ou através de uma acumulação mais exten siva, produzindo desequilíbrios ambientais e situações de risco com repercussões à saúde humana, que serão objetos da descrição de s te artigo.

O Estado de Ma to Grosso é marcado, mais acen tu ad a men te nas regiões do Cerrado e Floresta, por um fluxo de desmatamento e implantação de indústrias de madei ra e de agropecuárias de gado e soja, do sul para o norte do Estado (Nascimen to \& Drummond, 2003; Piaia, 2003; Viana, 2000).

O processo produtivo industrial-florestal tem causado gran des impactos negativos sobre a saúde dos trabalhadores, e s ten den do-se à população e ao ambi en te local/ regional, poden do atingir outros Estados. Segundo Franco \& Dru ck (1997) e Mach ado, Porto \& Freitas (2000), este potencial de expansão de riscos existe porque há uma estreita relação entre o ambien te intra e o extrafabril dos espaços industriais, ampliandoo raio de ação e mobilidade dos riscos de adoecimento, configurando assim uma redefinição das populações afet adas.

Al m eida \& Zu bl er (2000) e Ba rcellos (2000) referem que os produtos florestais em Mato
Grosso, a partir da transformação da madeira, envolvem trabalhadores que utilizam técnicas a rtesanais e máquinas pesadas, na extração das toras. $\mathrm{Na}$ fase de industrialização da madeira, es te processo utiliza outros trabalhadores que l a boram em galpões/barracões industriais (serrarias, laminadoras, beneficiadoras e fábricas de compensado) manipulando máquinas antigas/obsoletas, não automatizadas, de baixa produtividade, sem as devidas pro teções e migradas de outras regiões on de os madei rei ros já extra í ram a madei ra industrial.

As etapas produtivas dessa indústria em Ma to Grosso são: corte das árvores da floresta; transporte das toras até as indústrias - serrarias ou laminadoras; transformação primária em tábuas/vi gas ou lâminas de madei ra; transporte das tábuas/vigas para as beneficiadoras que fazem a tra $\mathrm{n}$ s formação sec un dá riaem portas, pisos, forros ou transporte das lâminas para as fábricas de compensados; transporte dos produtos para os portos de ex portação ou para as reven dedora s, para uso na construção civil e indústrias movel eiras; e geração e des tino adequado e inadequado de resíduos (Almeida \& Zubler, 2000; Ba rcellos, 2000). Segundo vários a utores, entre eles Barcellos (2000), Souza, Blank \& Calvo (2002), Thélin (2002), Leal (2005) e em Panorama Setorial (2005), em todas essas etapas da produção conformam-se situações de ris cos sociais, tecnológicos, er gonômicos e organizacionais que produzem doenças e aciden tes relacionados ao trabalho, com alta incidência de graves seqüelas e mutilações, tra zen do grande repercussão na vida social dos trabalhadores.

A relação saúde-trabalho-doença, compreendida a partir do caráter sócio-histórico, tem como determinação o modo como o Homem se apropria da natureza em um dado momento, por meio do processo de trabalho, baseado no grau de desenvolvimen to das forças produtivas e das relações sociais de produção (Laurell, 1983). Ou, para Porto \& Mat tos (2000): Pod emos analisar qualquer situação ou even to de risco como um produto histórico cujos determinantes e condicionantes mais gerais encontramse na fo rmação das soci edades e setores econô micos dentro dos quais em presas e situações reais de trabalho se realizam.

Nes te estu do analisou-se o processo produtivo das indústrias de tran s formação da madeira, para se conhecer as situações de riscos e os a gravos à saúde dos trabalhadores que laboravam nessas unidades, durante o ano de 2000. 
Há várias propostas de abordagens empíricas para a coleta de dados nos locais de trabalho enfocando o processo de produção e sua relação com a saúde dos trabalhadores. A proposta elaborada por Oddone (1986), a partir da prática do movimento sindical italiano, e a ad a ptada por Laurell \& Nori ega (1989) para os sindicatos de trabalhadores mexicanos usam técnicas participativas de geração e interação de conhecimen tos para ação transformadora darealidade. A técnica de "árvore de causas", de origem na França, também com metodologia participa tiva dos operários, analisa os acidentes de trabalho ocorridos, buscando as falhas técnicas, organizacionais e ergonômicas, até concluir com as causas gerenciais e sociais (Bin der, Mon teau \& Almeida, 1995).

Outra técnica, a Análise In terdisciplinar e Participativa de Aciden tes (AIPA), emerge da saúde pública, particularmente no campo da saúde do trabalhador, como estra té gia que analisa o processo de trabalho ampliando para além das causas imediatas dos aciden tes e permitin do maior aproximação com os trabalhadores (Machado, Porto \& Freitas, 2000).

A técnica do "mapa de riscos", inserida na legislação de segurança e Medicina do Trabalho no Brasil, através da NR 05 - portaria 25/94 (Brasil, 2004a), é a mais utilizada pelo movimento sindical brasilei ro (com adaptações), pelo sistema de fiscalização do Ministério do Trabalho e Emprego - MTE ou pelos serviços de Saúde do Trabalhador do Si s tema Único de Sa ú de - SUS. Este "mapa" foi ad a pt ado do modelo operário italiano e, na sua con fecção, deverão participar os técnicos e os trabalhadores, tan to nas avaliações como nos processos decisórios de gerenciamen to das situações de riscos (Mattos \& Freitas, 1994). Neste estudo utilizou-se metodologia derivada do mapa de riscos, com técnicas da engenharia, da medicina e incorporação de técnicas das ciências sociais.

As indústrias da madei ra estão distribuídas espacialmente no Estado, com con cen tração de $86 \%$ nas regiões on de há floresta e madei ra industrial, ou seja, na região norte, noroeste e oes te de Ma to Grosso. As "cidades-pólos" das madeireiras são Sinop, Alta Floresta, Juína, Guarantã do Norte, São José do Rio Cl a ro, Cáceres e Cuiabá, as quais aglutinam os 42 municípios pesquisados. No ano de 2000, as indústrias madei rei ras do Estado de Ma to Grosso somavam 1.749 unidades, empregavam 30.081 trabalhadores e processaram 2,6 milhões de $\mathrm{m}^{3}$ de madeira em toras, segundo o Anuário Esta- tístico de Ma to Grosso (2002) ou 7,5 milhões de $\mathrm{m}^{3}$, segundo o Ibama (2002). A diferença dos dados ocorre porque as informações do Anuário/MT se baseiam em informações do IBGE/ PEVS e os do Ibama, nas Autorizações de Transportes de Produtos Florestais - ATPF's. Segundo Mizuta \& Portela (2005), ambos os dados são subdimensionados, pois o prim ei ro, que se baseia em informações empresariais, busca evasão de tributos fiscais; e o segundo inclui ATPF's falsas, para encobrir o desmatamen to ilegal.

Os dados de Comunicação de Aci den tes de Trabalho (CAT) do Anuário Estatístico do MPS (2005) mostram a relevância deste estudo quando se analisam os acidentes de trabalho nas indústrias da madeira de Ma to Grosso. Estas contribuíram, em média, com 15\% do total de acidentes ocorridos nos anos de 2000 a 2003, os quais ocupam, em números absolutos, o segundo lugar de acidentes e óbitos, situando-se depois dos aciden tes das indústrias de alimentos e antes da pecuária e agricultura. Estes dados se referem apenas aos trabalhadores com vínculo empregatício formal (CLT), expressando, segundo Si lva (2000), apenas $11 \%$ dos aciden tes de trabalho. Isto porque há $89 \%$ de subnotificação em Cuiabá, sendo, possivelmente, maior nos municípios do interior do Estado. Ou, segun do Machado \& Gómez (1995), Wünsch Filho (1999) e Cordei ro (2002), existe cerca de $80 \%$ de subnotificação de acidentes de trabalho no Brasil.

Do total geral de 4.252 aciden tes de trabalho ocorridos em Ma to Grosso em 2000, 103 foram a óbito, enquanto no grupo das indústrias da madeira ocorreram 607 acidentes e, destes, 13 foram fatais. Se compara rmos com o Brasil, no mesmo ano, veremos que a incidência de aciden tes de trabalho foi de 1.259/100mil trab., sem elhan teà de Ma to Grosso, que foi de 1.242/100mil trab. Mas, enquanto a mort alidade no Brasil foi de 9/100mil trab., em Ma to Grosso ela foi de 28/100mil trab., ou seja , três ve zes maior. A letalidade no Brasil foi de 85/10 mil acidentes e em Ma to Grosso foi de 239/10 mil aciden tes, ou seja, quase três ve zes mais, sugerindo maior precariedade das condições de trabalho e/ou pior qualidade na assistência médica ao trabalhador acident ado e/ou maior notificação dos aci dentes grave-fatais e/ou su bn otificação dos demais na região. Ao observar os mesmos dados do ano de 2003, os indicadores para o Brasil apontaram uma diminuição, enquanto em Ma to Grosso, todos aumentaram, 
inclusive a letalidade. Segundo Breilh (1999), is toé típico de processo recen te de industrialização em regiões semelhantes à Amazônia, localizadas na China, Índia e vários países Africanos.

A partir desses dados, ob serva-se que os eventos ligados ao trabalho não têm se evi denci ado no Brasil, com toda sua magnitu de e vi olência, sendo menos revelados ou mais escamoteados em Ma to Grosso. Conhecer a realidade de saúde/trabalho/doença dos trabalhadores do setor madeirei ro na região é rel evante para compreender a organização deste espaço como processo político-social.

\section{Metodologia}

Es teé um estu do de ti po transversal descritivo de prevalência, em que foram levantadas as situações de ris cos à saúde através da técnica de mapa de riscos e se realizou diagnósticodínico e social dos operários das indústrias de transformação da madeira em Ma to Grosso, numa perspectiva de análise da determinação social do processo saúde-trabalho-doença. A correl ação estreita entre a configuração do processo de trabalho e os padrões de agravos não se torna imediatamen te evidente, mas na análise a través de técnicas da medicina e da engenharia aliadas às das ciências sociais pode-se avaliar as situações de riscos e inferir os determinantes sociotécnicos do processo de saúde.

O proj eto foi planejado conjuntam en te entre a UFMT-ISC e Senai-MT, aprovado pela Coordenação de Ex tensão e Comissão de Ética em Pesquisa da UFMT (Hospital Universitário) e executada de maneira interinstitucional e multidisciplinar. Os res pectivos propósitos foram assim delineados: a) a UFMT - ISC propon do-se a ampliar sua atuação baseada na Integração Docente Assistencial (IDA) realizada pelos professores e alunos do intern a to ru ral da medicina e enfermagem (estágio curricular e obrigatório), no norte do Estado, região onde se localizam $86 \%$ das madei rei ras; e b) o SenaiMT, necessitando de diagnóstico da situação saúde-trabalho-doença, financiou a pesquisa e estimulou a participação dos empresários nesta avaliação. En con tra ram-se obstáculos patronais à participação dos sindicatos de trabalhadore s, prevista na metodologia, limitando parcialmente a análise do processo de trabalho.

Foram elaborados dois ro tei ros ti po checklist, o primei ro para mapear os ris cos à saúde de $100 \%$ das indústrias madei reiras do Estado que aderissem ao projeto e se localizassem a menos de 30 quilômetros da sede do município. O segundo roteiro, de avaliação sócio-clínico-ocupacional, foi adaptado do modelo de história dínico-ocupaci onal de Rigot to (1994), incluindo-se nível de escolaridade, situação sindical, condição salarial, ti po de vínculo empregatício e medidas da acuidade visual. A meta foi avaliar $20 \%$ do total dos trabalhadores de cada grupo de pos to de trabalho homogêneo, em cada indústria, escolhidos aleatoriamente, cujas anamneses foram realizadas em ambulatórios médicos/enfermagem organizados nas s edes das indústrias, man ten do-se a privacidade dos avaliados.

Nestes mesmos postos de trabalho amostrados foram também avaliados (medidos) os níveis de ruído (com aparelho decibilímetro) e iluminação (com aparelho luxím etro), seguindo-se as normas NR-15-anexo 01 (Brasil, 2004b) e NBR 5413/82 (ABNT, 2004), incluindo estas informações nos mapas de riscos ocupacionais. Para a avaliação de pro teção das máquinas foram analisadas partes móveis (lâminas de corte, polias e engrenagens), dassificando-se como "pro tegida" quando aqu elas partes e seus equipamentos elétricos e/ou mecânicos acoplados es tives em pro tegidos. Averiguou-se o fornecimento de equipamentos de pro teção individual (EPI's), por meio dos estoques, notas fiscais de compras e entrevistas com os trabalhadores.

\section{Resultados e discussão}

A execução da pesquisa ocorreu durante os 12 meses do ano de 2000, quando foram visitadas as madeireiras e elaborados, após consentimento, 1.389 mapas de ris cos (774 serrarias, 121 laminadoras, 449 ben eficiadbras e 45 fábricas de compensados) de um total das 1.749 indústrias, pois 9 não permitiram a realização do levantamento; 146 distavam mais de 30 quilômetros da sede do município; e 205 foram desativadas duran te o ano. Nas indústrias estudadas laboravam 21.607 trabalhadores, dos quais, após consentimen to, foram examinados 4.381 ; destes, a penas 3\% eram mulh eres, todas labora $\mathrm{n}$ do em a tivid ades-meio. Os dados obtidos foram anotados nas respectivas fichas de cada trabalhador e no mapa de risco de cada indústria, sendo po steriorm ente digitados através do programa E PI INFO, versão 6.04b (Dean, 1999), con formando dois bancos de dados: Levantamento de 
situações de riscos ocupacionais e Avaliação clínico-social dos trabalhadores.

\section{Pa trões anti democráti cos e trabalhadores po u co organizados}

É importante de st acar que em 134 madei reiras os pesquisadores foram acompanhados por m em bros das CIPA's, $h$ aven do esporad ica mente a participação de alguns técnicos de segurança. Em 204 indústrias, os pesquis adores foram recebidos e orientados pelos gerentes/donos, enquan to nas em presas men ores (até 20 trabalhadores) não houve este acompanhamen to. Os sindicatos de trabalhadores participaram da pe s quisa em 21 indústrias e ten t a ramparticipar em outras 58, on de foram impedidos pelaclasse patronal. Is to parece ter servi do de desestímulo às entidades sindicais, já que abandonaram o acompanhamen to dos demais trabalhos.

No processo de "proibição" de participação dos sindicatos na produção de conhecimento, concluiu-se, em avaliações conjuntas com os sindicalistas, que se tratava de impedir suas entidades de usarem as informações a serem obtidas para tran s formar a realidade de vida/saúde dos trabalhadores das madei reiras, como veremos a seguir.

Além disso, a situação con figu rada su gere a pouca organização e/ou poder de pressão dos trabalhadores, ex pressa nos baixos níveis de filiação nos sindicatos de base, que ch ega ao máximo de $23 \%$, nos setores mais especializados, como ben eficiadoras e fábricas de compensados, localizadas na sede do município. Quanto mais distante da sede do município se localizava a fábrica, menor era a taxa de sindicalização ( $0 \%$ em $30 \%$ das serrarias), sugerindo menor con trole dos trabalhadores sobre o processo de trabalho, refletin do na precarização das relações de trabalho e maior número de situações de riscos. Segundo Pignati (1996), esta baixa sindicalização e po u co movimento sindical na defesa da saúde no trabalho foram também observados na região na década passada, mas, comparativamente, nota-se a ampliação da desmobilização nos últimos anos.

\section{Men or sindicalização e especialização, maior distância $=$ maior precarização}

As 1.389 indústrias de transformação de madeira pesquisadas estavam instaladas em 895 barracões (prédio térreo com as laterais abertas), que abrigavam as 774 serrarias e as 121 laminadoras. As 449 beneficiadoras e as 45 fábricas de compen sado estavam instaladas em 494 galpões (prédio térreo com as laterais fechadas). Constatou-se que a maioria desses ambientes de trabalho apre s en tou situações semelhantes de riscos à saúde, diferindo em intensidade e na característica dos trabalhadores, permitindo compará-los por setor, distância da cidade, sindicalização e outras correlações.

Analisando a tabela 1 notamos que as serrarias e laminadoras, que fazem a transform ação primária das toras de madeira, são as indústrias nas quais os trabalhadores laboram maior quantidade de horas/dia, com menores salários e maiores percentuais de vínculos informais, compara tiva men te aos outros dois setores. Estes dados se articulam com o fato de que esses trabalhadores, em sua maioria, são possivelmen te advindos do desemprego rural/urbano, menos especializado, com menor escolaridade e men or taxa de sindicalização.

\section{Tabela 1}

Caracterização dos setores e dos trabalhadores das indústrias madei rei ras de Ma to Grosso, 2000.

\begin{tabular}{|c|c|c|c|c|c|}
\hline \multirow[t]{2}{*}{ Ca ra cterização } & \multicolumn{5}{|c|}{ Setor } \\
\hline & Serraria & Laminadora & Ben eficiadora & $\begin{array}{c}\text { Fáb.de } \\
\text { Compensado }\end{array}$ & Total \\
\hline Totais indústrias pesquisadas & 774 & 121 & 449 & 45 & 1.389 \\
\hline № total de trabalhadores & 13.894 & 2.561 & 3.702 & 1.450 & 21.607 \\
\hline № de trab. pesquisados & 2.803 & 538 & 742 & 290 & 4.381 \\
\hline$\%$ de trab. pesquisados & $20,2 \%$ & $20,2 \%$ & $20,0 \%$ & $20 \%$ & $20,3 \%$ \\
\hline № de horas trab./dia (média) & $10 \mathrm{~h} 30 \mathrm{~m}$ & $9 \mathrm{~h} 45 \mathrm{~m}$ & $8 \mathrm{~h} 45 \mathrm{~m}$ & $8 \mathrm{~h} 30 \mathrm{~m}$ & $9 \mathrm{~h} 45 \mathrm{~m}$ \\
\hline № salário mín mens.(média) & 1,8 s.m. & 2,2 s.m. & 3,1 s.m. & 3,2 s.m. & 2,1 s.m. \\
\hline$\%$ de trabalhos formais & $54 \%$ & $59 \%$ & $81 \%$ & $85 \%$ & $60,8 \%$ \\
\hline$\%$ de sindicalização & $8 \%$ & $11 \%$ & $21 \%$ & $23 \%$ & $11 \%$ \\
\hline
\end{tabular}


Quando se analisam as informações das serrarias (Tabela 2) e se relacionam as condições de trabalho com a distância entre as indústrias e a sede do município, verifica-se que nas localizadas nas sedes, o número de horas trabalhadas/dia é de, no mínimo, 9 horas e 30 minutos, chegando a 11 horas e 30 minutos, quando estas madeireiras distavam 30 quilômetros da cidade; para os trabalhos formais, estes passam do percen tual de $61 \%$ na sede para $28 \%$ nas empresas localizadas no "mato". Observa-se que o aumento da carga horária trabalhada e de vínculos informais é diretamente proporc i onal à localização/distância das indústrias em relação à da sede município.

Ao contrário, se analisarmos os dados das indústrias de tra nsfomação secundária (ben eficiadoras e fábrica de compensados), verificamos que os números de horas trabalhadas são menores e os salários são maiores que os das serrarias. Este fato pode estar associado ao maior grau de especialização e qualificação escolar (vi de item escolarid ade) na execução de sta tarefa, à maior taxa de sindicalização e à localização destas fábricas nas sedes dos municípios, possibilitandomaior fiscalização/controle pelo Estado e maior poder de pressão/negociação dos trabalhadores.

As estratégias patronais, que fazem parte da história do processo de trabalho sob o capitalismo, tro u xeram poucos benefícios e muitos prejuízos à liberdade e à saúde dos trabalhadores. Na ordem capitalista, o con trole do tempo tem sido um dos elemen tos para disciplinar e "domesticar" o trabalhador, pois este rompeu com o tem po natu ral e passou a ser regi do pelo tempo do capital: pelo tempo que é valor (Marx, 1985). Assim, excesso de horas traba- lhadas, para além das 8 horas/dia ou 44 horas/semana, extrapolação comum na atividade industrial da madeira, com certeza é a estratégia mais usada de "extração" de mais-valia absoluta. Provavelmente porque, pelo alto grau desuca te a men toda maioria das máquinas, torna-se difícil a obtenção de mais-valia relativa pelo aumento da produtividade/trabalhador. Am bos os casos, porém, implicam maiores de sga stes à saúde dos trabalhadores.

\section{Morar na peri feria das cidades ou nas colônias do patrão}

Das 4.381 histórias sócio-clínico-ocupacionais, avaliaram-se dados sobre alcoolismo, tabagismo, estado nutricional, hábitos de lazer e tipo de moradia, que podem ser descritos como "hábi tos de vida" com influência na quali$\mathrm{d}$ ade de vida den tro e fora da fábrica.

O alcoolismo e o tabagismo foram referidos por $34 \%$ dos trabalhadores. O alcoolismo variou de $17 \%$ em menores de 18 anos, para $44 \%$ nos de 40-50 anos e o tabagismo va riou de $14 \%$ para $53 \%$ nas mesmas idades. Sobre o estado nutricional, en con trou-se $1,4 \%$ abaixo do peso; $67,8 \%$ com peso normal; $25,0 \%$ com sobrepeso; e $5,8 \%$ obesos. Observa-se que esses dados de hábitos de vida não demonstram grande relevância se avaliados de forma isolada, além de não terem apresentado diferenças significativas nos diversos setores produtivos.

Quanto aos hábitos de lazer verificou-se que $21 \%$ dos trabalhadores jogam futebol nos finais de semana (metade nos campos das fábricas); o utros $13 \%$ vão aos campos assistir aos jogos; $17 \%$ se reúnem com amigos em bares, casas e clubes para se "alimentar, b a ter papo e

\section{Tabela 2}

Caracterização dos trabalhadores, sindicalização, moradia e máquinas, de acordo com as distâncias das serrarias das sedes dos municípios. Ma to Grosso, 2000.

\begin{tabular}{|c|c|c|c|c|c|}
\hline \multirow[t]{2}{*}{ Ca ra cterização } & \multicolumn{5}{|c|}{ Localização } \\
\hline & Sede & $10 \mathrm{Km}$ & $20 \mathrm{Km}$ & $30 \mathrm{Km}$ & Total \\
\hline № total de serrarias & 419 & 165 & 102 & 93 & 774 \\
\hline № total de trabalhadores & 9.358 & 2.475 & 1.224 & 837 & 13.894 \\
\hline № de trab. pesquis adbs & 1.893 & 490 & 251 & 169 & 2.803 \\
\hline № de horas tra b./dia (média) & $9 \mathrm{~h} 30 \mathrm{~min}$ & $10 \mathrm{~h} 30 \mathrm{~min}$ & $11 \mathrm{~h} 10 \mathrm{~min}$ & $11 \mathrm{~h} 30 \mathrm{~min}$ & 10h30min \\
\hline № salário mín.mens.(média) & 2,1 s.m. & $1,8 \mathrm{~s} . \mathrm{m}$ & 1,6 s.m. & 1,5 s.m. & 1,8 s.m. \\
\hline$\%$ de trabalhos formais & $61 \%$ & $48 \%$ & $31 \%$ & $28 \%$ & $54 \%$ \\
\hline \% de sindicalização & $20 \%$ & $15 \%$ & $11 \%$ & $5 \%$ & $8 \%$ \\
\hline \% que moram em colônias & $10 \%$ & $28 \%$ & $35 \%$ & $36 \%$ & $17 \%$ \\
\hline \% de máquinas pro tegidas & $41 \%$ & $20 \%$ & $17 \%$ & $16 \%$ & $33 \%$ \\
\hline
\end{tabular}


in gerir bebida alcoólica socialmente’' ( sic); outros 35\% fazem lazer em casa "ven do tel evisão, cozinhando, cons ertando a casa ou dormindo muito" (sic); $12 \%$ realizam as duas atividades an teriores e $9 \%$ responderam que "não fazem nada" (sic). Estes dados revelam a falta de equ ipamentos sociais/públicos para o lazer dos trabalhadores. Mo s tra também a neces sid ade de sses operários de auxiliarem nos afazeres domésticos, trabalhando, portanto, nos dias do descanso semanal.

Além disso, pela característica não especializada na maioria das atividades produtivas desta indústria e excesso de mão-de-obra desempregada, os patrões pou co inves tem no lazer necessário para promover a saúde de seus em pregados. Di ferente desta estratégia, Giroletti (2002) mostra que, historicamente, os empresários têm investido em lazer e serviços de saúde, para manter o vínculo e disciplinar os trabalhadores.

Em relação ao ti po de moradia, detectou-se que $68 \%$ moravam em bairros populares da periferia das cidades, $15 \%$ moravam em vilas ou distritos rurais e outros $17 \%$ moravam nas "colônias" cedidas pela classe patronal. Observou-se ainda, durante as visitas de pesquisas nas madei reiras, que a maioria destas "colônias" se localizava nos pátios internos das fábricas, on de moravam principalmente as famílias dos trabalhadores com maior especialização e/ou com muita experiência prática. O estu do demonstra que essas colônias torn avamse mais numerosas quan to mais se afastava da cidade e, assim, a média de trabalhadores que habitavam este tipo de moradia passava de $10 \%$ para $36 \%$ quando as serrarias se afastavam no sen tido do "mato" (Ta bela 2). Esta possível "es tratégia" patronal pode significar maior cooptação e con trole da vida social den tro e fora das fábricas, "coincidindo" ainda que qu a n to mais no "mato", maior o nível de exploração dos trabalhadores, como temos descri to. Além disto, os trabalhadores que moravam nestas colônias ditavam a dinâmica da produtividade, pois a maioria era form ada por serradore s, ali$\mathrm{n}$ h adores e motoristas, cuja ativid ade iniciava o processo de trabalho, seqüenciando as outras a tivid ades.

Segundo Girolet ti (2002), o anti go modelo de fábrica com vila operária ou, mais recentemente, de acordo com Pico lli (2004), os acampamentos, colônias e as cidades-em presa, subordinados ao setor produtivo, formam um sis tema de dominação que permite a expansão do poder exercido pelos em presários do interior da unidade produtiva para a vida social e privada, no âmbi to da comunidade.

\section{Só $12 \%$ consegu em trabalhar após os 40 anos}

Dos trabalhadores avaliados, verificou-se que $4 \%$ possuem idade en tre $14-17$ anos; $33 \%$ de $18-25$ anos; $23 \%$ de $26-30$ anos; $28 \%$ de 31 40 anos; 9\% de 41-50 anos e 3\% mais de 51 anos. Estas informações mostram que $89 \%$ dos trabalhadbres deste setor possuem idade abaixo de 40 anos, provavel $m$ en te devido ao tipo de ativid ade altamen te de sgastante.

As situações de riscos já analisadas e comuns nestas madei reiras provavelmente levaram à diminuição brusca dos trabalhadores em a tividade após os 40 anos de idade. Podemos supor, também, que parte destes trabalhadores adoeceu e se acidentou, en qua n toos mutilados e outros seqüelados foram dem i ti dos ou morreram; o utros, não su portando o ritmo, o esforço físico/mental e o estresse, interrom peram o contra to de trabalho. Além disto, como a maioria das máquinas do setor era ob soleta e o processo produtivo pouco autom a tizado, teriam selecio$n$ ado e recrutado trabalhadores com maior força física e higi dez para o de sem penho das atividades, leva n doà discriminação da maioria dos trabalhadores acima de 40 anos de idade.

Não se encontrou grande diferença na distri buição etária nos vários setore $s$, com exceção dos men ores de 18 anos, sen do que $63 \%$ deles concentram-se nas serrarias, on de é maior a precarização das condições de trabalho. A presença de menores nestas fábricas pode ser interpret ada pela men or fiscalização das institu ições do Estado e/ou por ser um setor de serviço menos especializado e/ou por serem trabalhadores não organizados. Na prática, a con tratação de menores resulta em maior lu cro para a classe patronal. Isto contraria a Portaria 06/2001/MTE (Brasil, 2005), que proíbe o trabalho de men ores de 18 anos em atividades insalubres, como madei reiras, pa ra não com prometer o de s envo lvimento do adole scente.

\section{Maioria analfabeta e/ou com primei ro grau escolar incompleto}

Quanto à escolaridade formal verificou-se que $10 \%$ dos trabalhadores eram analfabetos; $74 \%$ tinham o ensino fundamental incompleto e $7 \%$ completo; $6 \%$ possuíam o ensino médio 
in completo e $2 \%$ completo; e apenas seis trabalhadores tinham o curso su perior completo. Averiguou-se também que esse perfil de escolaridade foi repetido, em média, nos diferentes setores produtivos, exceto quando se analisaram as serrarias e suas distâncias das cidades, observan do-se uma diminuição da escolaridade quantomais se afastavam das sedes, em direção ao "ma to". Is to pode mostrar que, para as indústrias não necessitaram de maior nível de escolarização, su pon do que suas máquinas são de fácil manipulação, buscou-se selecionar a "força física" na População Economicamente Ativa (PEA) das regiões madei reiras que apresenta o perfil escolar semelhan tes aos em pregados (IBGE/PNAD, 2002).

\section{Ausência de sanitários e refeitórios}

As condições sanitárias/higiênicas mostra que os banhei ros estão presentes em $64 \%$ das indústrias, mas $45 \%$ de stes não atendiam às recomendações da NR 24; 62\% das empresas possuíam bebedouros de água potável, mas $53 \%$ de s tes apre s en $\mathrm{t}$ avam condições inadequ adas de uso, como ausência de filtros, copos de uso coletivo e outras irregularidades que não atendiam às normas da NR 24; apenas 3,6\% das indústrias dispunham de refeitórios para os trabalhadores. Nas serrarias a 30 quilôme- tros da cidade estes equipamentos praticamente não ex i s tem.

\section{Máquinas despro tegidas, faltam EPI's e extin tores de incêndio}

Durante a elaboração dos mapas de riscos foram analisadas 8.433 partes móveis (lâminas de corte, polias e engren a gens) de 5.292 máqu inas, nos 4.381 pos tos de trabalho pesquisados. Verificou-se que apenas $31 \%$ destas en contravam-se com a devida proteção, $45 \%$ estavam parcialmente pro tegidas e $24 \%$ eram totalmente de sprotegidas. Para avaliação de situação de ri s co, consideramos des protegidas as máquinas parcialm en teprotegidas, som a ndo69\% de de sproteção.

Na tabela 3, verifica-se ainda que as máqu inas das serrarias e das laminadoras estavam menos protegidas, em com pa ração com as máquinas das beneficiadoras e das fábricas de compensados, que estavam com percentual maiorde proteção.

Ao se analisar a pro teção das máquinas das serrarias (Tabela 2 ), verificou-se que a proteção passa de $41 \%$ em serrarias na cidade, para a penas $16 \%$ nas situ adas a uma distância de 30 quilômetros da sede. Esta alta desproteção de máquinas e a baixa pres ença de equipamentos contra incêndios, mais uma vez confirmam o

\section{Tabela 3}

Prevalência (\%) de máquinas pro tegidas, nível de ruído, ex tin tores/hidrantes e forn ecimento EPI's dos setores das indústrias madei reiras de Ma to Grosso, 2000.

\begin{tabular}{|c|c|c|c|c|c|}
\hline Setor & Serraria & Laminadora & Beneficiadora & $\begin{array}{c}\text { Fábrica de } \\
\text { Compensa do }\end{array}$ & Total \\
\hline Número de Po s tos de Trabalho & 2.803 & 538 & 722 & 290 & 4.381 \\
\hline Caracterização / Prevalência & $\%$ & $\%$ & $\%$ & $\%$ & $\%$ \\
\hline Máquinas protegidas & 28 & 30 & 48 & 46 & 31 \\
\hline Nível de ruído $<85$ dB & 0,5 & 13 & 22 & 35 & 8 \\
\hline Nível de ruído 86 - 95 dB & 10 & 61 & 58 & 39 & 26 \\
\hline Nível de ruído 96 - 105 dB & 52 & 26 & 18,5 & 24 & 41 \\
\hline Nível de ruído 106 - 115 dB & 37 & - & 2,5 & 2 & 24 \\
\hline Nível de ruído > 115 dB & 0,5 & - & - & - & 0,5 \\
\hline Extintor presente/adequ ado & 05 & 22 & 41 & 70 & 25 \\
\hline Hidrante presente/adequ ado & - & 15 & 40 & 50 & 9 \\
\hline EPI's - 3 ou mais tipos & 06 & 13 & 30 & 71 & 20 \\
\hline EPI's - parcial: 1 ou 2 tipos & 21 & 36 & 50 & 29 & 32 \\
\hline Não dispon ibilizam EPI's & 73 & 51 & 20 & - & 48 \\
\hline
\end{tabular}


a um en toda precaried ade das condições de trabalho, à medida que as indústrias se afastam das cidades.

O baixo fornecimen to de EPI's aos traba1 h adores (Tabela 3 ) mostra que, mesmo esta estratégia simples, de eficácia rela tiva, baixo custo e usada para mascarar a continuidade dos fatores de riscos e transferir a responsabilidade de pro teção ao corpo aos trabalhadores, é pouco acatada pelos empresários das madei reiras de Ma to Grosso. Observa-se que neste ramo de produção, a regra parece ser a máxima exploração da força de trabalho e/ou omissão do Estado fiscalizador e/ou baixa organização dos trabalhadores para exigir esse mínimo (EPI's) ou eliminar as situações de riscos.

\section{Excesso de ruído, iluminação adequada}

$\mathrm{Na}$ confecção do mapa de risco dos 4.381 postos de trabalho foi também realizada avaliação qu a n ti t a tiva de exposições ao ruí do, com o trabalhador e seu(s) instrumen to(s) de trabalho em ativid ade (Ta bela 3 ). Destetotal, 92\% a pres en ta ram índices altos de ruído, com nívei s acima de $85 \mathrm{Db}$, e apenas $8 \%$ apre sentaram níveis aceitáveis (NR15). Verifica-se na tabela 3 que o nível de ruído de $89 \%$ dos postos de trabalho das serrarias é dos mais altos e se concentram en tre 96 e $115 \mathrm{~dB}$, enquanto nas fábricas de compensados parte destas (35\%) apres entam níveis men ores que os $85 \mathrm{~dB}$ aceit á veis e $39 \%$ en tre 86 e $95 \mathrm{~dB}$, ou fora das normas.

Esta situação de estresse pelo ruído e seus agravos à saúde se potencializam por causa das má quinas obsoletas, despro tegidas, do aumento das horas trabalhadas e informalidade dos vínculos (Mendes, 2003). Acre s centa-se que esta precarização e as doenças relacionadas ao trabalho se ampliam à medida que as indústrias se afastam das cidades.

Nos mesmos pos tos de trabalho foram aferidos os níveis de iluminamen to, com o luxímetro, verificando-se que, do total, $12 \%$ apresentaram nível insatisfatóro (abaixo do nece ssário para o posto e idade); $3 \%$ acima; e $85 \%$ satisfatório (NBR-5413/82). Entretan to quando se analisa esse item, por setor, verifica-se que nas serrarias e laminadoras, que funcionam em barracões com laterais abertas, 95,6\% das medições estavam adequadas. Nas fábricas de compen sado e ben eficiadoras, instaladas em galpões com laterais fechadas, portanto com menor quantidade de luz natural, $76 \%$ das prensas e $47 \%$ das guilhotinas estavam com ní- veis de iluminação inadequ ados (abaixo do mínimo para o pos to e idade), assim como outras máquinas. Estes dados significam que os níveis foram satisfatórios apenas quando o trabalho dependeu de luz natural, economizando en ergia elétrica em detrimen to da saúde dos trabalhadores em postos de trabalho de manipulação de máquinas desprotegidas.

\section{Poucas CIPAS e outros grupos de prevenção ou con trole}

Observou-se que as Comissões Internas de Prevenção de Acidentes (CIPA’s) estavam presentes em 251 das 602 indústrias com mais de 20 trabalhadores, mas apenas 134 estavam funcionan do econ seguiram acompanhar os en trevistadores desta pesquisa, enquanto as demais não se en contravam organizadas, existindo apenas bu rocraticamente.

Os Serviços Especializados em Engenharia de Segurança e Medicina do Trabalho (SESMT) foram observados em 55\% das 214 indústrias com mais de 50 trabalhadores, onde esses serviços eram terceirizados. Também constavam nos seus arquivos os Programas de Prevenção de Ris cos Ambiental (PPRA) e os Programas de Con trole Médico e Sa ú de Ocupaci onal (PCM$\mathrm{SO})$. Dialoga ndo com pou cos médicos en contrados em serviço nas madeireiras, ob servamos que eles ainda atuam na visão da medicina do trabalho, subordinando-se como elemento de controle e reposição da força de trabalho, sem competência e/ou pressão para eliminar as situações de riscos (Fadel \& Pignati, 2005).

Apenas sete indústrias po s suíam programa regular de treinamento com cursos de operação de máquinas e seg u rança no trabalho. Verificou-se que dos 173 operadores de caldeiras, 118 possuíam o certificado de treinamen to, obrigatório pela Portaria 02/84/NR -13 (Brasil, 2004c).

\section{Pó de serra, fumaça e conservan tes de madeira estão no ar, nos olhos e na pele}

Os fatores de riscos químicos detectados nas madeireiras foram: pó de madeira, fumaças agrotóxicas e preservantes de madeira que estão distribuídos de acordo com sua utilização e setor produtivo. Nas serrarias observamos que o pó de madei ra expõe diret a m en te todos os serradores, alinhadores e de s top adores e, indiretamente, todos os trabalhadores, pois as laterais dos barracões são abertas e a ventilação leva o 
pó para todo o ambiente de trabalho. Além disso, não se detectou pre sença de nen hum sistema de aspiração de pó acoplado às serras. As fumaças da qu eima de resíduos de madeira estão presentes em $63 \%$ das serrarias, sendo que os locais de qu eima co tidiana distam em média 50 metros dos barracões; apenas 58 serrarias po ssuem fornos queimadores; o restante destas unid ades deposita os re sí duos em lixões ou fornecem para as laminadoras para servi rem de combustível para as caldeiras. Verificau-se ainda que 32 serra rias faziam o tratamento químico com inseticidas e fungicidas, como preservantes de madeira, estando envolvidos nesta atividade 102 trabalhadores, dos quais apenas 21 usavam filtros-respiradores adequ ados e somente 42 usavam luvas e aventais.

\section{Avaliação clínica e social: $36,5 \%$ mutilados e seqüelados}

$\mathrm{Na}$ avaliação clínica e social, foram examinados os 4.381 trabalhadores dos respectivos pos tos de trabalhos on de se avaliaram as con dições de riscos. A tabela 4 mostra dados sobre as lesões e doenças diagnosticadas/observadas. As qu eixas clínicas referidas pelos trabalhadores serão comentadas, provavel $m$ en te estarão correl acionadas com as situações de ri s cos e agravos.

Observa-se que a prevalência de mutilados (perda por acidente ou cirúrgica de parte do corpo, membros ou órgãos) é de 10,8\% dos trabalhadores pesquisados e em atividade nas madei reiras. Estas mutilações se deram principalmen te por cortes de serras, guilhotinas e prensas, acom eten do des departes de dedos, até todo o mem bro su perior ou inferior, resultantes da secção pelo aciden te ou por esmagamento e posterior retirada cirúrgica da parte lesada. Constatau-se que, mesmo com mutilações e lesões graves, muitos, após rec u pera ção, continuavam na ativa, embora parte dos lesionados provavelmente fora demitida do emprego, uma parcela estava de licença (seg u ro saúde) e outros tinham morrido. Verificou-se que outros trabalhadores $(25,7 \%)$ possuíam seqüelas de aciden tes de trabalho (exceto mutilações) como, por exemplo, secção de um ou vários músculos com perda parcial ou total das funções, cicatriz (es) na pele e/ou calosidade óssea por fratura, ou cegueira por trauma (destacase que 120 trabalh adores apresen t avam cegu eira unilateral, ou seja, 2,7\% dos pesquisados). Conclui-se que os acidentados incluem o somatório dos mutil ados e dos seqüelados, perf a- zen do $36,5 \%$ de prevalência de acidentes típicos no trabalho nas madeirei ras pesquisadas.

A alta su bn o tificação de aci den tes de trabalho em Ma to Grosso, já analisada neste arti go, faz com que não tenhamos o conhecimento exato desta realidade, fato este também relatado por Panosso Neto (2002,) em estudo das madei reiras, em municípios do interi or de Ma to Grosso. Observou ele que é difícil saber ao certo os números destes acidentes já que, quando oco $r$ rem, o geren te ou patrão bu sca prestar assistênci a ao acidentado e sua família, no sentido de evitar denúncia e futuros processos indenizatórios.

O estu do também mostrou, por meio de exame clínico, a alta prevalência de trabalhadores (Tabela 4) com deformidades da coluna vertebral $(28 \%)$ e vícios posturais de quadril/ombro/membros (24,6\%), assim como $43 \%$ relataram lombalgia, nas qu eixas referidas. Estas situações estavam relacionadas ao alto esforço e de sga s te físico de ste tipo de trabalho, dassificado como pesado na NR 15, além de condições ergonômicas inadequadas. Segundo Couto (2003) os distúrbios dolorosos da coluna vertebral (genericamen te denominados lombalgias e dorsalgias) constituem-sena maior causa isolada de transtorno de saúde e absen teísmo relacionados ao trabalho, sendo mais el evada em ocupações que ex i gem esforços físicos pesados, repetitivos ou contínuos.

Quanto às questões referen tes à visão, notase que $25,3 \%$ dos trabalhadores estudados apresentaram algum grau de deficiência na acuidade visual, para lon ge e/ou perto (Ta bela 4). Destes, $5,3 \%$ já faziam uso de len tes corretivas, enquanto $20 \%$ estavam trabalhando sem n en hum corretivo visual, em local de grave situação de risco, ampliada pelo baixo iluminamen to de muitos pos tos de trabalho, con forme já referido anteriormente. Além disto, 46\% a pres en ta ram conjun tivi te irrita tiva e/ou alérgica (Tabela 4), devido ao pó de madeira, fumaça de qu eima de resíduo e uso de produtos químicos, como descritos sobre as situações de ris cos químicos.

Estes agentes irrit a tivos e alergênicos referidos também con tribu em para as lesões dermatológicas alérgicas que aparecem em $8 \%$ da amostra. Além destas, foram detect adas outras lesões de pele como as lesões ativas e cicatriciais de leishmaniose em 9\%, denotando a gravidade da situação sanitária regional. Resultantes do atri to das mãos (sem uso de luvas) com a madei ra, observa ram-se calosidades extensas, profundas, do lorosas e limitantes de movimen- 
Tabela 4

Número e prevalência (\%) de trabalhadores com agravos (lesões e doenças) por setor das indústrias madei reiras de Ma to Grosso, 2000.

\begin{tabular}{|c|c|c|c|c|c|c|c|c|c|c|}
\hline \multirow{2}{*}{$\begin{array}{l}\text { Setores } \\
\text { Caracterização }\end{array}$} & \multicolumn{2}{|c|}{ Serraria } & \multicolumn{2}{|c|}{ Laminadora } & \multicolumn{2}{|c|}{ Ben eficiadora } & \multicolumn{2}{|c|}{$\begin{array}{c}\text { Fábrica } \\
\text { de Compensado }\end{array}$} & \multicolumn{2}{|c|}{ Total } \\
\hline & № & $\%$ & № & $\%$ & № & $\%$ & № & $\%$ & № & $\%$ \\
\hline № Trabalhadores por setor & 2.803 & 100 & 538 & 100 & 722 & 100 & 290 & 100 & 4.381 & 100 \\
\hline 1. Mutilados & 289 & 10,3 & 99 & 18,4 & 70 & 9,7 & 15 & 5,2 & 473 & 10,8 \\
\hline 2. Outros seqüel ados & 723 & 25,8 & 213 & 39,6 & 117 & 16,2 & 752 & 5,9 & 1.128 & 25,7 \\
\hline 3. Deformidades co luna vert. & 726 & 25,9 & 113 & 21,0 & 183 & 25,3 & 592 & 0,3 & 1.236 & 28,2 \\
\hline 4. Vícios postu rais & 504 & 18,0 & 336 & 62,5 & 180 & 24,9 & 58 & 20,0 & 1.078 & 24,6 \\
\hline 5. Deficiência acuidade vi sual & 562 & 20,0 & 105 & 19,5 & 151 & 20,9 & 73 & 25,2 & 891 & 20,3 \\
\hline 6. Alergia conjuntiva ocular & 1.632 & 58,2 & 112 & 20,8 & 216 & 29,9 & 58 & 20,0 & 2.018 & 46,1 \\
\hline 7. Hipertensão arterial grave & 98 & 3,5 & 22 & 4,1 & 26 & 3,6 & 11 & 3,8 & 157 & 3,6 \\
\hline Hipertensão art. m oderada & 103 & 3,7 & 21 & 3,9 & 25 & 3,5 & 15 & 5,2 & 164 & 3,7 \\
\hline Hipertensão arterial leve & 374 & 13,3 & 69 & 12,8 & 101 & 14,0 & 32 & 11,0 & 576 & 13,1 \\
\hline $\begin{array}{l}\text { 8. Lesão dérmica alérgica } \\
\text { (madeira e prod. químico) }\end{array}$ & 81 & 2,9 & 26 & 4,8 & 51 & 7,1 & 17 & 5,9 & 175 & 4,0 \\
\hline $\begin{array}{l}\text { 9. Lesão dérmica ( tinea alba, } \\
\text { pedis, co rporis) }\end{array}$ & 445 & 15,9 & 74 & 13,8 & 119 & 16,5 & 51 & 17,6 & 683 & 15,6 \\
\hline $\begin{array}{l}\text { 10. Lesão dérmica (calosidades } \\
\text { doloridas nas mãos) }\end{array}$ & 1.827 & 65,2 & 252 & 46,8 & 415 & 57,5 & 93 & 32,1 & 2.587 & 59,1 \\
\hline $\begin{array}{l}\text { 11.Lesão dérmica } \\
\text { (leishmaniose, cicatriz e ativa) }\end{array}$ & 308 & 11,0 & 43 & 8,0 & 24 & 3,3 & 13 & 4,5 & 388 & 8,9 \\
\hline 12.Varizes de mem bros inf. & 153 & 5,5 & 26 & 4,8 & 49 & 6,8 & 19 & 6,6 & 242 & 5,5 \\
\hline
\end{tabular}

tos de dedos e mão(s), em 59\% dos trabalhadore s. Estas lesões, s egun do Ali (1997) são provavelmente devidas à necessidade de se transportar manualmen te a madeira e seus produtos e baixo uso de EPI's. Observou-se o uso, por muitos trabalhadores, de luvas improvisadas com câmaras de ar de pneus. Notou-se a presença de tineas (corporis, pedis e alba) em $15 \%$ da amostra (Tabela 4).

Quantoà pres ença de hipertensão arterial, 20,5\% dos trabalhadores da amostra apresentaram esta doença (Ta bela 4), classificada em leve, moderada e grave. Na população em geral a prevalência é em torno de 15 a $20 \%$ sendo que, na distribuição por ramo produtivo, os trabalhadores do setor industrial e os motoristas de ônibus têm a prevalência da hipertensão arterial entre $17,3 \%$ e $21 \%$, en quan to no setor de serviços ela está en tre 11\% e 12,9\% (Dantas, 2003). A alta prevalência ob s ervada na amostra estudada sugere que o estresse ambiental/do trabalho deve ser um fator adicional a ser considerado na avaliação, assim como a precarização das condições de trabalho.

\section{Conclusão}

Ao descrever a relação saúde-trabalho-doença que ocorre no processo produtivo da indústria da madeira em Ma to Grosso, ob servou-se que existem situações de riscos à saúde que ocasionam even tos de ris cos (acidentes ou doenças). Verificou-se que suas causas imediatas estão no gerenciamento das indústrias e na atuação reguladora do Estado, facilitada pela baixa or ganização sindical dos trabalhadores .

Além do perfil de morbidade identificado para todos os setores da indústria madei reira no qual podemos destacar uma prevalência de 59\% de calosidades dolorosas nas mãos, 46\% com alergias de conju n tiva ocula res denotando desgastes específicos e freqüen tes ao trabalho ma nual em ambi en tes em poei rados. É particularmen te preocupante a existência de $10 \%$ de mutilados e $25 \%$ de seqüelados trabalhando Nas laminadoras esses percentuais chegam a $18 \%$ e $39 \%$, respectivamente, e vão a $62 \%$ os vícios posturais que em média estão presentes em $24 \%$ dos trabalhadores do setor. Configura-se uma população marcada pelos acidentes e deform ada pelo trabalho nas madeireiras. 
Uma caracterís tica recorren te no estudo é a precarização das condições de trabalho, observada nos men ores salários, vínculos informais, de sproteção das máquinas, alto nível de ruí do e baixo uso de EPI's, que possuem relação diret a com o aumen to da distância das indústrias para fora das cidades, em direção ao "mato". Neste mesmo sen tido acompanha uma menor sindicalização, maior carga horária, maior número de trabalhadores "controlados" morando nas colônias do patrão e maior prevalência de acidentados (mutilados/seqüel ados) e doenças relacion adas ao trabalho.

A realidade de saúde/trabalho/doença dos trabalhadores da indústria madei rei ra de Mato Grosso reflete o processo de desenvo lvimento insustentável em um Estado desregulado e o precário con trole social, explicando a máxima exploração da força de trabalho. Segundo Porto \& Mattos (2003), a produção de acidentes, das doenças, a destruição ambiental, assim como o esforço e a estratégia de co mbater estes problemas, expressam o valor político e econômico da vida das pessoas e do meio ambiente como um todo num dado co $n$ texto social.

\section{Colaboradores}

WA Pignati trabalhou na elaboração do projeto, na coleta compilação e análise dos dados e na redação final do artigo e JMH Mach ado participou na análise dos dados e na redação final do artigo.

\section{Agradecimentos}

Agradecemos à equipe de trabalho, especialmenteJanete Si lva (Senai), Alessand raStefan (Senai), O demir Ba rbosa (Senai), Ma rina Atanaka dos Santos (ISC/UFMT) e alunos do In tern a to Rural de Medicina e Enfermagem da UFMT que participaram desta pesquisa
A adoção de medidas para eliminação ou con trole das situações de ri s conão depen de somen te de soluções técnicas e gerenciais, mas de soluções políticas, con struídas nas relações de poder, que depen dem da capacid ade de articulação dos trabalhadores com os demais movi$m$ en tos sociais, com as universidades e com os técnicos e ge stores da saúde/ambiente, no senti do da construção do controle social da atividade produtiva.

As tec nologias em pregadas e suas formas de aplicação trouxeram para a região Amazônica um con ju n to de condições de apropriação e reprodução do espaço que não atingem do mesmo modo os grupos sociais. Elas modificam eventos, condições de vida e sua rede de relações de solidaried ade, induzidas por um proj eto de exclusão social e individualidade.

A extrema exploração e desproteção social a que estão submetidos os trabalhadores das indústrias madeirei ras de Mato Grosso ex pre ssa a violência social estrutural da sociedade nessa região. Na mesma forma e grau que tem se express ado na ocupação e de s truição da FlorestaAmazônica.

\section{Referências bibliográficas}

Ali SA 1997. Dermatoses ocupa cio na is. Fund acen tro, São Paulo. Almeida BC \& Zubler ES 1999/2000. O setor madeireiro de Mato Grosso. Senai-MT, Cuiabá.

Associação Brasilei ra de Normas Técnicas (ABNT)1982. Padrões e normas pa ra iluminação em ambi en te de trabalho, NBR 5413/82, Rio de Janeiro.

Ba rcellos P 2000. Transformação: a manipulação da madeira e suas con s eqüências nas atividades em que está envo lvida. Revista Proteção, ano XIII, maio:30-41.

Binder MCP, Almeida IM \& Monteau M 1995. Árvo re de causas: método de investigação de aciden tes de trabalho. $\mathrm{Pu}-$ blischer Brasil Editora, São Paulo.

Brasil, 2005. Anuário Estatísti co da Previdência Social . Dis ponível em <www.mpas.gov.br>. Acessado em 20/04/2005.

Brasil 2004a. Portaria 3.214/MTE - NR 5. Mapa de riscos, Porta ria no 25 / 1994. Manual de Legislação Atlas, Segurança e Medicina do Trabalho. Atlas SA, São Paulo.

Brasil 2004b. Port a ria 3.214/MTE - NR 15 anexo 1. Limitesde tolerância para ruídos. Manual de Legislação Atlas, Segurança e Medicina do Trabalho. Atlas SA, São Paulo.

Brasil 2004c. Portaria 3.214/MTE - NR 13. Caldeiras e vasos depressão. Manual de Legislação Atlas, Seg u rança e Med icina do Trabalho. Atlas SA, São Paulo.

Brasil, Ibama. 2001. Comercialização de produ tos madei reiros da Amazônia 1999-2000. Ministério do Meio Ambiente, Brasília. 
Brasil 2005. Portaria 06/2001/MTE. Dispõe sobre a proibição do trabalho do men or de 18 anos em local insalubre. Disponível em <http//www.mte.gov.br $>$. Acessado 20/06/05

Brasil, IBGE/PNAD 2002. Estatística de escolaridade formal por região e município. Disponível em <www.ib ge.gov.br>. Acessado em 20/04/2005.

Breilh J 1999. Eficácia del poder, retroceso del derecho y degrad ación del trabajo: el escenario regresivo de la salud laboral en América Latina. Anais do Encontro Nacional de Saúde do Trabalhador, Ministério da Saúde (série D, n.10), Brasília.

Cordei ro RC 2002. Subdiagn ó s ti co comprom ete políticas públicas. Pesquisa Fapesp, junho.

Co uto HA 2003. Doenças osteomusculares relacionadas com o trabalho: coluna e membros inferiores, pp. 1541-1571. In R Mendes. Patol ogia do trabalho. 2a ed. Editora Atheneu, São Paulo.

Dantas J 2003. Patologia cardiovascular relacion ada ao trabalho, pp. 1295-1328. In R Mendes. Patologia do trabalho. 2a ed.. Editora Atheneu, São Paulo.

Dean AG et al. 1999. E PI INFO, Versão 6: um sistema de processamen to de tex to, ban co de dados e estatística para epidemiologia em microcomputadores. Tradução Marilda L S. Guedes.

Dru ck G \& Franco T 1997. A degradação do trabalho e os riscos industriais no contexto da globalização, produtivas e daspolíticas neoliberais, pp. 15-32. In T Fra nco (org.). Trabal ho, riscos indu strial e meio ambiente: rumo ao desenvolvimen to sustentável? Ed itora UFBA, Salvador.

Fadel LCV \& Pignati WA 2005. Medicina do trabalho: ciência ou su b s erviência? Arti go en tregue em fevereiro de 2005 para Ciência \&e Saúde Col etiva, Rio de Janeiro.

Fiemt/Lodi 2002. A distribuição e organização das madeirei ras de Ma to Grosso. Instituto de Pesquisa, Edwaldi Lodi, Cuiabá.

Giroletti D 2002. Fábrica: convento e disciplina. Editora Universidade de Brasília, Brasília.

Laurell AC 1983. A saúde-doença como processo social, pp. 133-158. In ED Nunes. Medicina social: aspectos históricos e teóricos. Global, Rio de Janeiro.

Laurel AC \& Noriega 1989. Processo de produção e saúde: trabalho e desgaste operário. Hucitec, São Paulo.

Leal MFM 2005. A qualidade de vida na indústria madeireira na região amazônica. Disponível em <www. amazon.com.br/nf.leal/qualidade $>$. Acessado em 13/04/2005.

Mach ado JHM \& Gomez CM 1995. Acidentes de trabalho: con cepções de dados, pp. 117-142. In MC Minayo (org.). Os muitos brasis, saúde e população na década de 80. Hucitec, São Paulo.

Machado JMH, Porto MFS \& Freitas CM 2000. Pers pectivas para uma análise interdisciplinar e participativa de aci den tes (AIPA) no con tex to da indústria de Processo, pp. 49-81. In Freitas, Porto \& Machado. Acidentes industriais ampliados. Fiocruz, Rio de Janeiro.

Marx 1985. O capital: crítica da economia politica. 2a ed. CHED, São Paulo.

Ma to Grosso, Anuário Estatístico 2002. Anuário Estatísti co do Estado de Mato Grosso, Secretaria de Planejamento. SEPLAN-MT/Central de Texto, Cuiabá.
Mello AM \& Théry H 2003. L'Ètat brésilien et l'envi ronn em ent em Amazonie: evolutions, contradictions et conflits. L'Espace géographique, EG 2003-1, Paris:3-20

Men des R (org.) 2003. Patologia do trabalho. 2a ed., vol. 1 e 2. Editora Atheneu, São Paulo.

Mizuta R \& Portela F 2005. Da floresta ao deserto, pp. 121-128. Veja. Editora Abril, São Paulo.

Nascimento E P \& Dru m m ond JA 2003. Amazônia, dinamismo econômico e con servação ambiental. Ed. Ga ramond, Rio de Janeiro.

Pa n orama Setorial 2005. Ativid ades florestais na Argentina são de riscos. Buenos Aires; Celulose Online. Disponível em $<$ http://www. celuloseonline.com.br $>$. Acessado em 3/03/2005.

Panosso Neto A 2002. Geopol ítica, agricultores e madei reiros na frente oeste de colonização. Editora UCBD, Campo Grande.

Passos MM 1999. Amazônia: tel edetecção e colonização. Editora Unesp, São Paulo.

Piaia I I 2003. Geografia de Mato Grosso. Edunic, Cuiabá.

Piccoli F 2004. Amazônia: a ilusão da terra prometida. Editora Fiorelo, Sinop.

Pignati WA 1996. Trabalho e saúde: ações sindicais na defesa da saúde no trabalho. Dissertação de mestrado em Saúde e Ambiente, UFMT/ISC, Cuiabá.

Porto MFS 2000. Considerações sobre a dinâmica de regulação dos riscos indu striais e a vuln erabilidade da socied ade brasileira, pp. 47-170. In Herculano, Porto \& Freitas (org.). Qualid ade de vida \& riscos ambientais. Ed. UFF Niterói, RJ.

Porto MFS \& Freitas CM 1997. Análise de ris cos tecnológicos no campo da saúde de trabalhador. Cadernos de Saúde Pública 13(supl. 2):59-72.

Porto MFS \& Mattos UAO 2003. Estratégias de prevenção, gerenciamen to de ris cos e mudança tecnológica, pp. 1721-1739. In Men des R. Patologia do tra balho. 2a ed. Atheneu, São Paulo.

Rigotto MR 1994. Investigan do a relação entre saúde e trabalho, pp. 159-177. In LE Rocha et al. (orgs.). Isto é trabalho de gente? Vida doença e trabalho no Brasil. Vozes, Petrópolis.

Santos M 2002. A natu reza do espaço: técnica e tempo, razão e emoção. Edusp, São Paulo.

Si lva C R 2000. A subnotificação dos aciden tes de trabalho em Cuiabá e Várzea Grande-MT. Mon ografia de especialização, UFMT/ISC, Cuiabá.

Souza V, Blank VLG \& Calvo MC 2002. Cenários típicos de trabalho na indústria madei reira. Revi sta de Saúde Pública 36(6):702-708.

Thelin A 2002. Fatal acidentes in Swedish farming and fores try, 1988-1997. Swed en Soft Science 40(2002):501517.

Viana GA 2000. Relatório do desenvolvimen to (In)sustentável da Amazônia - O caso das madei reiras. Câmara dos Deputados, Brasília.

Vi centin G \& Min ayo CG 2003. Sa ú dee de senvolvimento econômico na Amazônia. Ciência \& Saúde Coletiva 8(4):1069-1085.

Wünsch Filho V 1999. Reestruturação produtiva e acidentes de trabalho no Brasil. Cadernos de Saúde Pública 15:41-51.

Arti go apre sen tado em 18/06/2005

Aprovado em 8/08/2005

Versão final apresentada em 8/08/2005 